\title{
Correlation between Preferentially Expressed Antigen of Melanoma and Tumour Necrosis Factor-Related Apoptosis-Inducing Ligand Gene Expression in Different Types of Leukaemia Patients
}

\author{
Wenhui Zhang ${ }^{\mathrm{a}}$ Kaikai Chi ${ }^{\mathrm{b}}$ Yin Zhang ${ }^{\mathrm{a}}$ Baogen Ma ${ }^{\mathrm{a}} \quad$ Jie Shi ${ }^{\mathrm{a}} \quad$ Yuqing Chen $^{\mathrm{a}}$ \\ Pingchong Lei ${ }^{\mathrm{a}}$ Yulong $\mathrm{Li}^{\mathrm{a}}$ Kai Sun ${ }^{\mathrm{a}}$ \\ ${ }^{a}$ Department of Hematology, Henan Provincial Hospital, Zhengzhou University, and bepartment of Urology, The First \\ Affiliated Hospital of Henan University of Traditional Chinese Medicine, Zhengzhou, PR China
}

\section{Key Words}

Preferentially expressed antigen of melanoma - Tumour necrosis factor-related apoptosis-inducing ligand .

Leukaemia

\begin{abstract}
Introduction: Tumour necrosis factor-related apoptosis-inducing ligand (TRAIL) down-regulation by preferentially expressed antigen of melanoma (PRAME) is a general phenomenon in different types of solid tumours, but research on the correlation between PRAME and TRAIL gene expression in leukaemia patients is rare. Method: PRAME and TRAIL expression was detected in bone marrow samples from 80 newly diagnosed acute leukaemia (AL) patients and 40 chronic myeloid leukaemia (CML) patients using TaqManbased real-time quantitative PCR methods, and a linear correlation analysis was performed on their levels of expression. A total of 15 normal bone marrow samples from individuals with non-malignant haematological diseases served as normal controls. Results: PRAME expression was higher in both $A L$ and CML patients compared to controls (both $p<0.001$ ). CML patients in both blast crisis $(B C)$ and the accelerated phase (AP) had significantly higher PRAME levels than CML patients in the chronic phase (CP) $(p=0.006$ and 0.0461 , re-
\end{abstract}

\section{KARGER}

E-Mail karger@karger.com

www.karger.com/aha spectively). TRAIL expression was higher in both the acute myeloid leukaemia (AML) group and the acute lymphoblastic leukaemia (ALL) group than in the controls $(p=0.039$ and 0.047, respectively). In contrast, CML patients had lower TRAIL levels than controls $(p=0.043)$, and TRAIL expression in CML patients in the advanced phases (BC and AP) was significantly lower than in CML-CP patients $(p=0.006)$. In CML patients, there was a significant inverse correlation (Spearman's $R=-0.6669, p<0.0001)$ between PRAME and TRAIL gene expression, while a greater significant inverse correlation was found in patients in the advanced phases (BC and AP) $(R=-0.6764)$. In addition, no correlation was observed in AML and ALL patients. Conclusion: The simultaneous detection of PRAME and TRAIL gene expression may be helpful to monitor condition changes in leukaemia patients and evaluate therapeutic effects in clinical practice, particularly in CML patients.

(c) 2013 S. Karger AG, Basel

\section{Introduction}

Preferentially expressed antigen of melanoma (PRAME) is a tumour antigen recognised by cytotoxic $\mathrm{T}$ cells (CTLs) and was originally identified in a melanoma 
patient [1]. It is expressed in various malignant tumours, including solid tumours and haemopoietic neoplasia; however, it is not expressed or only weakly expressed in normal tissues [2]. Tumour necrosis factor-related apoptosis-inducing ligand (TRAIL), a new antitumour molecule, is a type II membrane protein belonging to the TNF superfamily [3], and it is abnormally expressed in a variety of cancers (higher or lower expression than normal tissues). It has been confirmed that TRAIL down-regulation by PRAME is a general phenomenon in different types of solid tumours; De Carvalho et al. [4] also found this phenomenon in chronic myeloid leukaemia (CML) patients. However, research on the correlation between PRAME and TRAIL gene expression in different types of leukaemia patients is relatively rare. In this study, we determined the expression of these two genes in bone marrow mononuclear cells from different types of leukaemia patients and performed a linear correlation analysis on this expression.

\section{Materials and Methods}

\section{Patients and Controls}

Bone marrow samples were collected from 80 de novo patients with acute leukaemia [AL: 61 acute myeloid leukaemia (AML) and 19 acute lymphoblastic leukaemia (ALL)] and 40 patients with CML from June 2011 to July 2012. AL was classified according to the French-American-British (FAB) classification. The CML diagnosis of patients enrolled in this study was confirmed by Philadelphia chromosome and BCR-ABL rearrangement detection. CML was classified into the chronic phase (CP), accelerated phase (AP) and blast crisis (BC) according to the criteria of the International Bone Marrow Transplant Registry. All bone marrow samples were tested for PRAME and TRAIL expression with quantitative RTPCR. In addition, a control group of 15 normal bone marrow samples from individuals with non-malignant haematological diseases was tested, and the K562 cell line was used as a positive control and for sensitivity tests. The study was approved by the research ethics committee of our hospital, and informed consent was obtained from all participants.

\section{Primer and Probe Design}

Primers and probes were designed using Primer-Express software (PE Biosystems). Each probe was labelled with a fluorescent $5^{\prime}$-reporter dye (FAM: 6-carboxy-fluorescein) and a $3^{\prime}$-quencher (TAMRA: 6-carboxy-tetramethyl-rhodamine). The PRAME-specific primers and probe were as follows:

forward primer, $5^{\prime}$-CTCTATGTGGACTCTTTATTTTTCCTTAGA-3';

reverse primer, $5^{\prime}$-CGAAAGCCGGCAGTTAGTTATT-3'; probe, $5^{\prime}$-CTGGATCAGTTGCTCAGGCACGGTGA-3'.

The TRAIL-specific primers and probe were as follows:

forward primer, $5^{\prime}$-CTCTGTGTGGCTGTAACTTACGTG- ${ }^{\prime}$; reverse primer, $5^{\prime}$-CAAGCAATGCCACTTTTGGA-3'; probe, $5^{\prime}$-CGAGCTGAAGCAGATGCAGGACAAGTAC-3'. The GAPDH housekeeping gene was used to normalise PRAME and TRAIL expression.

\section{Real-Time Amplification Protocol}

Total RNA was extracted using TRIzol reagent (Invitrogen) according to the manufacturer's instructions. The RNA concentration and purity were determined by spectrophotometry. Reverse transcription was carried out with a Prime Script RT-PCR kit (Ta$\mathrm{KaRa}$, Japan). The standard reverse transcription reaction volume was $10 \mu \mathrm{l}$ and contained $2 \mu \mathrm{l}$ of $5 \times \mathrm{RT}$ buffer, $300 \mathrm{ng}$ of template mRNA, $0.5 \mu$ l of oligo dT primer $(50 \mu \mathrm{M}), 0.5 \mu \mathrm{l}$ of RT enzyme mix, $2 \mu \mathrm{l}$ of random 6 -mers $(100 \mu \mathrm{M})$ and $2 \mu \mathrm{l}$ of $\mathrm{RNase}$-free $\mathrm{dH}_{2} \mathrm{O}$. This mixture was incubated at room temperature for $15 \mathrm{~min}$ and then maintained in a heat block at $85^{\circ} \mathrm{C}$ for $5 \mathrm{~s}$. For PRAME, TRAIL and GAPDH transcripts, $2 \mu \mathrm{l}$ of target $\mathrm{cDNA}$ was added to $20 \mu \mathrm{l}$ of PCR mix containing $10 \mu \mathrm{l}$ of Universal PCR Master Mix, $400 \mathrm{nM}$ of each primer and $800 \mathrm{nM}$ of the probe according to the manufacturer's protocol. The GAPDH housekeeping gene and the genes of interest were amplified in parallel. The reaction was initiated at $95^{\circ} \mathrm{C}$ for $30 \mathrm{~s}$, followed by 40 cycles of denaturation at $95^{\circ} \mathrm{C}$ for $5 \mathrm{~s}$ and annealing/extension at $60^{\circ} \mathrm{C}$ for $33 \mathrm{~s}$. The data were recorded as threshold cycle $(\mathrm{Ct})$ values with an ABI StepOne plus System (Applied Biosystems, Calif., USA) using analytical software from the same manufacturer.

\section{Quantification with Real-Time RT-PCR}

The average Ct value of GAPDH was subtracted from the average $\mathrm{Ct}$ value of each gene of interest. The calibrator was the mean Ct value obtained from 15 control marrow samples, which were assessed in parallel. The $\Delta \mathrm{Ct}$ value obtained in leukaemia samples was then subtracted from the $\Delta \mathrm{Ct}$ value obtained from the calibrator, giving a $\Delta \Delta \mathrm{Ct}$ value. Because the amplification efficiencies for PRAME, TRAIL and GAPDH were comparable, the amount of mRNA of each gene normalised to GAPDH was given by the relation $2^{-\Delta \Delta C t}$. A bone marrow sample was considered positive for PRAME expression if the expression level was 10-fold higher than the mean expression in control samples [5]. A bone marrow sample was considered positive for TRAIL expression if the expression level was 1-fold higher than the mean expression in control samples.

\section{Sensitivity and $C V$ Value}

K562 cDNA was serially diluted 10-fold in water, and the limit of PRAME detection with real-time RT-PCR was $10^{-5}$ (fig. 1). The cDNA of mononuclear cells from a normal bone marrow sample was serially diluted 10 -fold in water, and the limit of TRAIL detection was $10^{-5}$ (fig. 1). Intra- and inter-assay reproducibility was determined using 10-fold serial dilutions of K562 cDNA (1:1 to $\left.1: 10^{-5}\right)$. The intra- and inter-assay CVs for real-time RT-PCR were 2.4 and $3.1 \%$, respectively.

\section{Statistical Analysis}

Statistical analyses were carried out with GraphPad Prism, version 5.00 for Windows (GraphPad Software, San Diego, Calif., USA). Experimental values were compared using the Mann-Whitney U test, the Kruskal-Wallis test or the non-parametric Spearman's rank correlation test. Differences between experimental groups were considered significant at $\mathrm{p}<0.05$. 
Fig. 1. a Sensitivity of real-time RT-PCR in detecting PRAME expression in K562 cDNA serially diluted 10 -fold in water. b Sensitivity of real-time RT-PCR in detecting TRAIL expression in the cDNA of mononuclear cells from a normal bone marrow sample serially diluted 10 -fold in water.

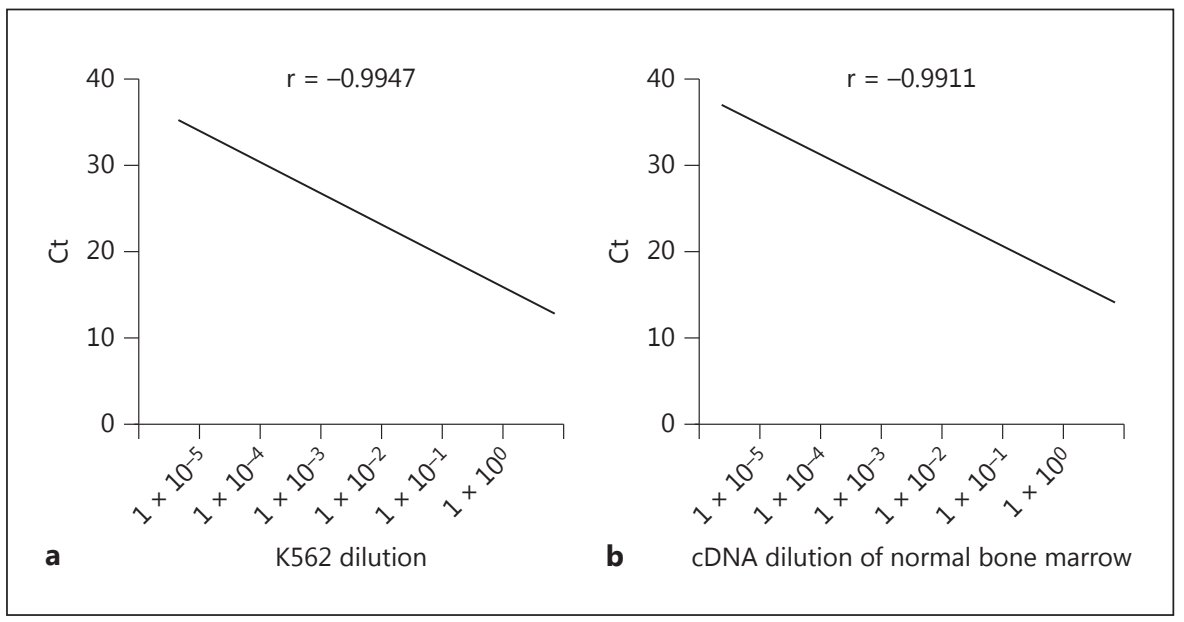

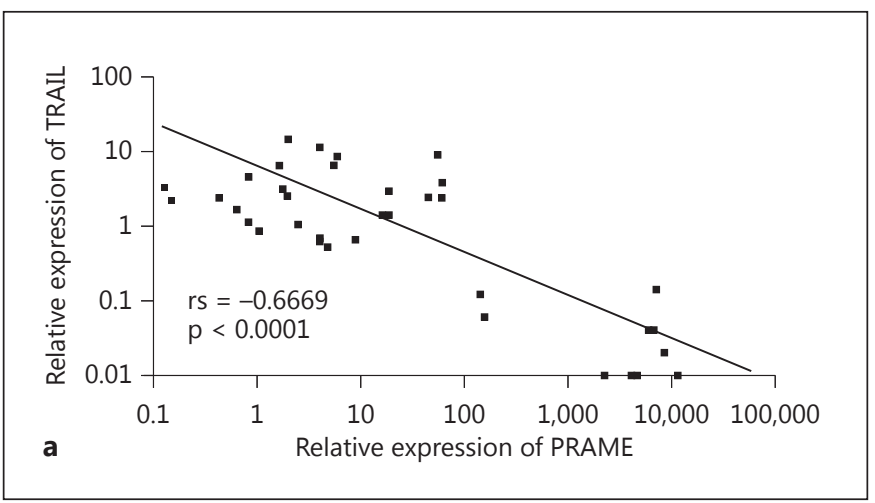

Fig. 2. a Correlation between relative PRAME and TRAIL expression in all CML patients (Spearman's $\mathrm{R}=-0.6669, \mathrm{p}<0.0001$ ). b Correlation between relative PRAME and TRAIL expression in CML patients in the advanced phase (BC and AP) (Spearman's $\mathrm{R}=-0.6764, \mathrm{p}=0.0002)$. c Correlation between relative PRAME and TRAIL expression in CML patients in the CP (Spearman's $\mathrm{R}=0.1968, \mathrm{p}=0.4821$ ).

\section{Results}

\section{Correlation}

A correlation analysis was first performed on PRAME and TRAIL gene expression in CML patients, and the result showed that there was a significant negative correlation (Spearman's $\mathrm{R}=-0.6669, \mathrm{p}<0.0001$ ) between the expression of these two genes (fig. 2), in agreement with
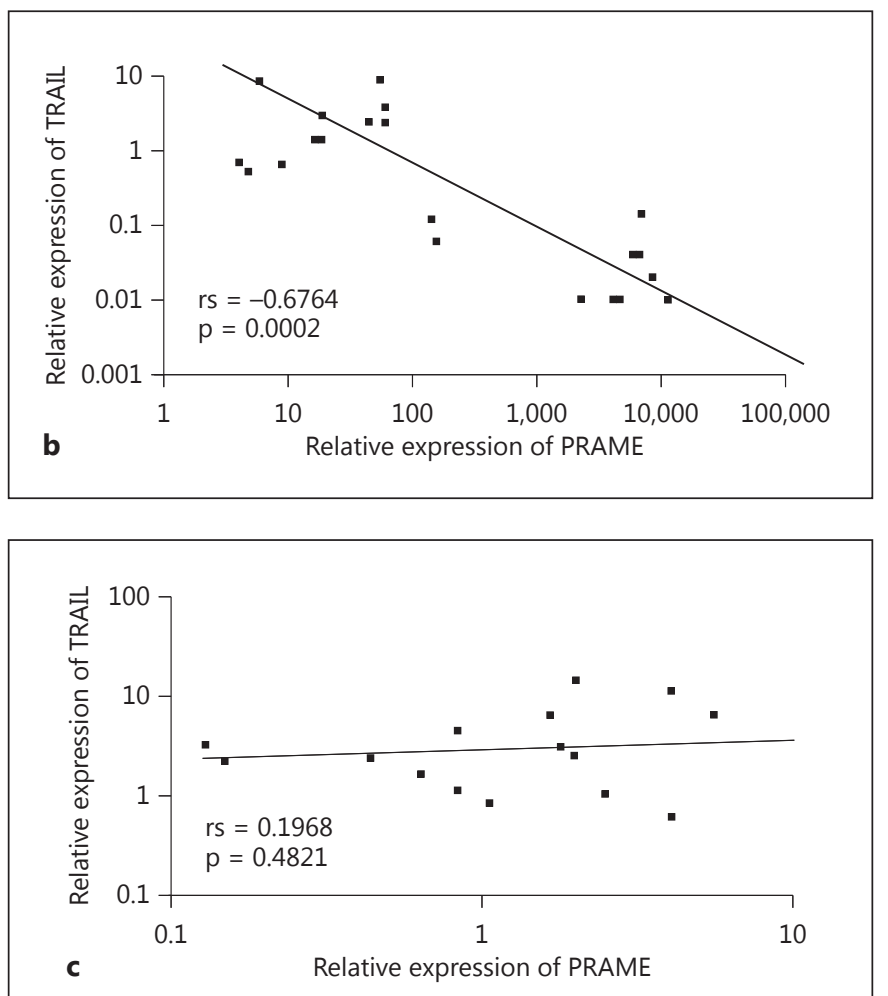

De Carvalho et al. [4]. In addition, a more significant correlation $(\mathrm{R}=-0.6764, \mathrm{p}=0.0002)$ was observed in patients who were in an advanced phase (BC or AP), but there was no correlation ( $\mathrm{p}=0.4821)$ in CML-CP patients (fig. 2). Unexpectedly, in AML ( $\mathrm{p}=0.7322)$ and ALL ( $\mathrm{p}=$ 0.6235 ) patients, no correlation was observed between the levels of these two genes (fig. 3). 

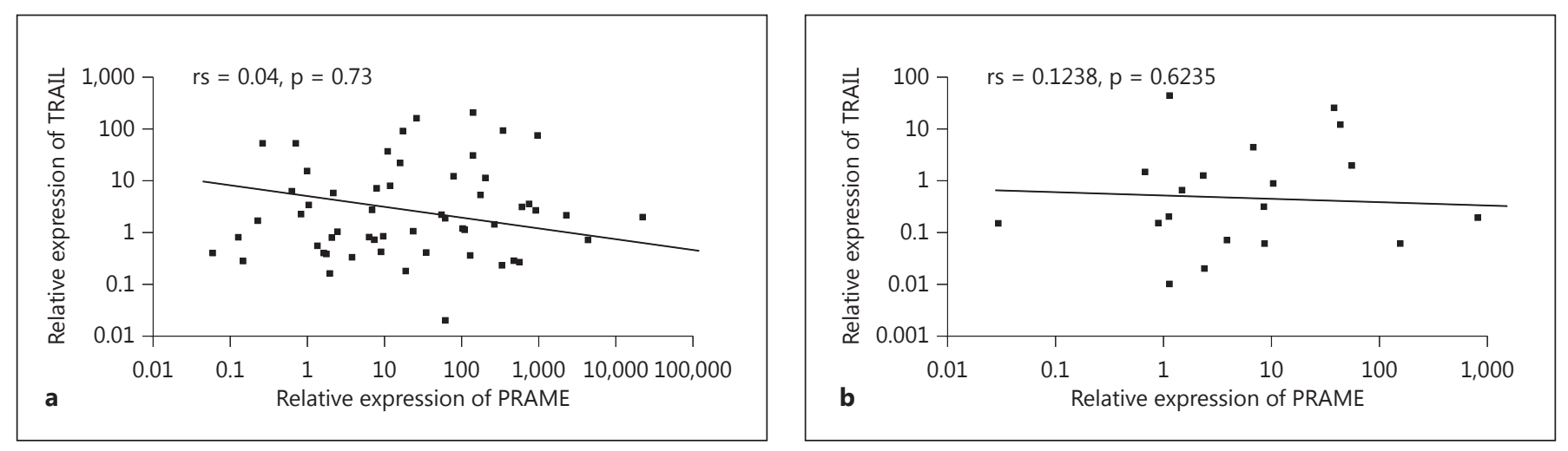

Fig. 3. a Correlation between relative PRAME and TRAIL expression in AML patients (Spearman's R = 0.04676, $\mathrm{p}=0.7322$ ). $\mathbf{b}$ Correlation between relative PRAME and TRAIL expression in ALL patients (Spearman's $\mathrm{R}=$ $0.1238, \mathrm{p}=0.6235)$.

Table 1. Expression of PRAME in bone marrow cells from leukaemia patients by real-time RT-PCR

\begin{tabular}{lrclc}
\hline Sample & $\mathrm{n}$ & $\begin{array}{l}\mathrm{n} \text { of } \\
\text { positive }\end{array}$ & $\begin{array}{l}\text { Ratio of } \\
\text { positive, } \%\end{array}$ & $\begin{array}{l}\text { Relative } \\
\text { expression }\end{array}$ \\
\hline AML M1 & 3 & 1 & 33.33 & $95.92 \pm 49.2$ \\
AML M2 & 27 & 15 & 55.55 & $868.66 \pm 233.98$ \\
AML M3 & 10 & 6 & 60 & $629.95 \pm 146.91$ \\
AML M4 & 13 & 6 & 46.15 & $101.22 \pm 26.7$ \\
AML M5 & 8 & 2 & 25 & $34.27 \pm 14.49$ \\
Total & 61 & 30 & 48.39 & $523.46 \pm 152.29$ \\
CML-BC & 15 & 12 & 80 & $3,844.86 \pm 739.89$ \\
CML-AP & 10 & 4 & 40 & $985.6 \pm 278.17$ \\
CML-CP & 15 & 2 & 13.33 & $6.92 \pm 4.38$ \\
Total & 40 & 18 & 45 & $1,690.82 \pm 994.13$ \\
ALL & 19 & 7 & 36.84 & $261.78 \pm 88.84$ \\
Control & 15 & 1 & 6.67 & $5.49 \pm 3.82$ \\
\hline
\end{tabular}

${ }^{a}$ Results are expressed as mean \pm SD for relative expression compared to normal bone marrow, using the relation $2^{-\Delta \Delta C t}$.

Table 2. PRAME and TRAIL expression of AML-M2 samples with AML1-ETO at diagnosis and at CR using real-time RT-PCR

\begin{tabular}{lrrlr}
\hline Sample & $\begin{array}{l}\text { Expression } \\
\text { of PRAME } \\
\text { at diagnosis }\end{array}$ & $\begin{array}{l}\text { Expression } \\
\text { of PRAME } \\
\text { at CR }\end{array}$ & $\begin{array}{l}\text { Expression } \\
\text { of TRAIL } \\
\text { at diagnosis }\end{array}$ & $\begin{array}{l}\text { Expression } \\
\text { of TRAIL } \\
\text { at CR }\end{array}$ \\
\hline P1 & $2,272.40$ & 43.11 & 20.48 & 6.71 \\
P2 & $12,865.30$ & 4.08 & 12.21 & 17.29 \\
P3 & 340.14 & 0.59 & 1.23 & 8.23 \\
P4 & 770.69 & 30.70 & 3.56 & 0.64 \\
\hline
\end{tabular}

$\mathrm{P}=$ AML-M2 patient with AML1-ETO.

${ }^{\text {a }} \mathrm{CR}$ is defined as $<5 \%$ leukaemia cells in the bone marrow.
Relative Expression of PRAME in Patients with

Different Types of Leukaemia

The PRAME levels were either extremely low or undetectable in control samples. PRAME expression in patients with AML and ALL was higher than in controls ( $\mathrm{p}<0.001$ for both), and it was detected at high levels in AML M3 (60\%), AML M2 (55.55\%) and AML M4 patients (46.15\%) (table 1). We also found that the PRAME expression in 4 patients with $\mathrm{t}(8 ; 21)$ was much higher than other AML subtypes. Likewise, PRAME expression was also higher in the CML group compared to controls $(\mathrm{p}<0.001)$ (table 1). The difference in PRAME expression between the CML-BC and CML-CP groups, and between the CML$\mathrm{AP}$ and CML-CP groups was statistically significant $(\mathrm{p}=$ 0.006 and 0.0461 , respectively). Furthermore, the difference between CML-BC and CML-AP patients was statistically significant $(p=0.045)$. These results confirmed those of De Carvalho et al. [4] and Radich et al. [6], who demonstrated that PRAME was up-regulated during CML progression. Interestingly, we also found that there was an inverse correlation $(\mathrm{r}=-0.35, \mathrm{p}=0.019)$ between PRAME levels and the quantity of bone marrow blast cells in AML patients. Figure 4 shows PRAME expression in different types of leukaemia patients.

\section{PRAME and TRAIL Levels in $t(8 ; 21)$ AML Patients}

Assessed for Minimal Residual Disease

The gene expression of PRAME and TRAIL in four $\mathrm{t}(8 ; 21)$ AML patients was monitored at presentation and at complete remission (CR) (table 2). Three of the patients reached CR after 1 cycle of standard $3+7$ induction chemotherapy (doxorubicin $30 \mathrm{mg} / \mathrm{m}^{2} /$ day or idarubicin 12 $\mathrm{mg} / \mathrm{m}^{2} /$ day for 3 days plus cytarabine $100 \mathrm{mg} / \mathrm{m}^{2} /$ day for 
Fig. 4. Relative PRAME levels in control and patient groups (expressed in $\Delta \mathrm{Ct}$ ). Horizontal lines represent the mean relative PRAME expression of each study group. A high $\Delta \mathrm{Ct}$ value indicates a low PRAME expression level.

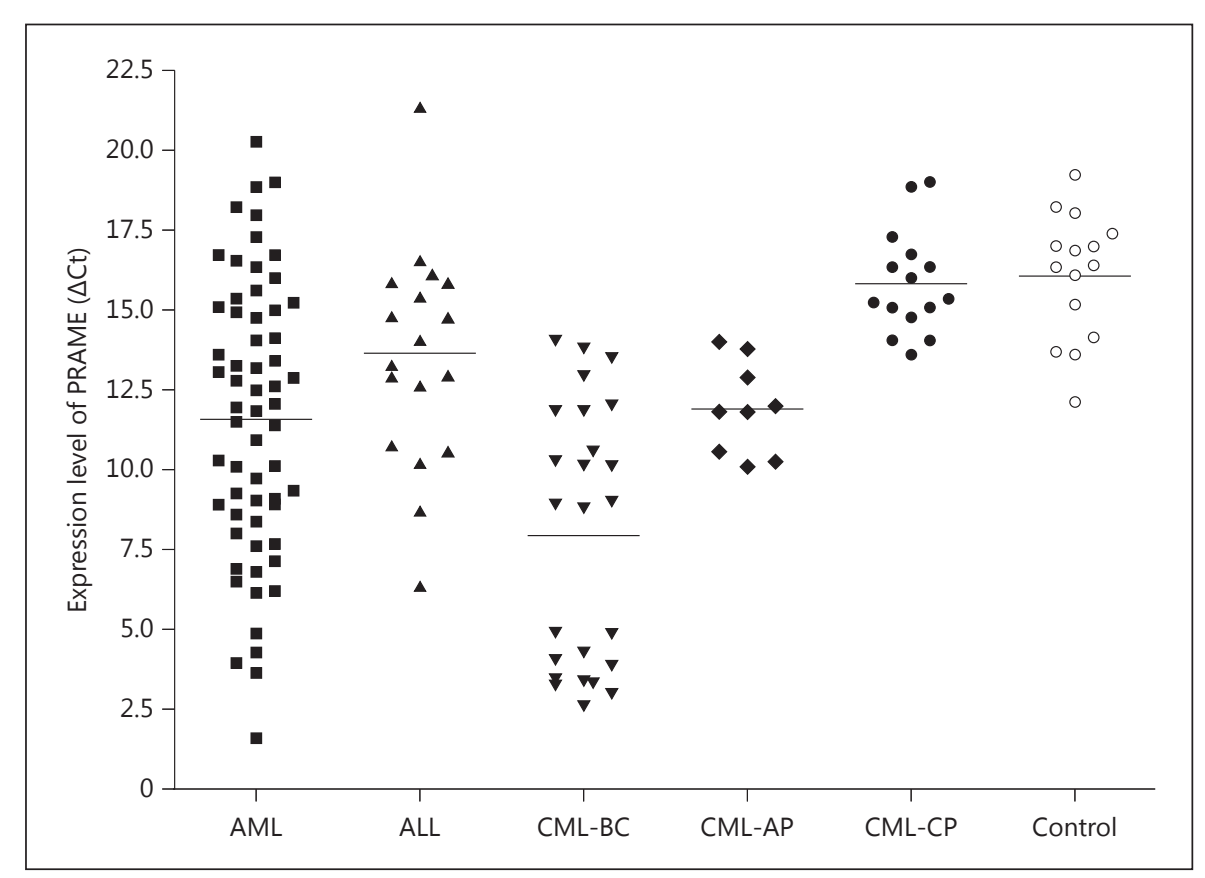

7 days), and 1 patient reached CR after 2 cycles of induction chemotherapy. Interestingly, a marked decrease in PRAME expression was observed in all four samples tested between diagnosis and CR. Moreover, TRAIL expression increased in two samples and decreased in two samples.

\section{Relative TRAIL Expression in Patients with Different Types of Leukaemia}

TRAIL expression was significantly higher in AML and ALL patients compared to controls ( $\mathrm{p}=0.039$ and 0.047 , respectively) (table 3 ), and it was expressed at similar levels in different subtypes of AML $(\mathrm{p}=0.376)$. The difference in TRAIL expression between AML and ALL patients was not statistically significant $(\mathrm{p}=0.157)$. TRAIL expression was lower in CML patients than in controls $(\mathrm{p}=0.043)$, and its expression in CML cases at an advanced phase was significantly lower than in CML$\mathrm{CP}$ patients $(\mathrm{p}=0.006)$. The difference in the TRAIL level between CML-BC and CML-AP patients was not statistically significant $(\mathrm{p}=0.23)$. Figure 5 shows TRAIL expression in patients with different types of leukaemia.

\section{Discussion}

PRAME is over-expressed in a variety of neoplasia, such as melanoma, Hodgkin lymphoma and myelocytic and lymphocytic leukaemia, but its expression is low or
Table 3. Expression of TRAIL in bone marrow cells from leukaemia patients by real-time RT-PCR

\begin{tabular}{lcclr}
\hline Sample & $\mathrm{n}$ & $\begin{array}{l}\mathrm{n} \text { of } \\
\text { positive }\end{array}$ & $\begin{array}{l}\text { Ratio of } \\
\text { positive, } \%\end{array}$ & $\begin{array}{l}\text { Relative } \\
\text { expression }^{\mathrm{a}}\end{array}$ \\
\hline CML-BC & 15 & 1 & 6.67 & $0.54 \pm 0.43$ \\
CML-AP & 10 & 1 & 10 & $0.47 \pm 0.42$ \\
CML-CP & 15 & 3 & 20 & $1.14 \pm 0.86$ \\
Total & 40 & 5 & 12.5 & $0.75 \pm 0.59$ \\
AML & 61 & 35 & 57.38 & $10.15 \pm 8.16$ \\
ALL & 19 & 10 & 52.63 & $8.96 \pm 5.65$ \\
Control & 15 & 3 & 20 & $1.65 \pm 0.91$ \\
\hline
\end{tabular}

a Results are expressed as mean \pm SD for relative expression compared to normal bone marrow, using the relation $2^{-\Delta \Delta \mathrm{Ct}}$.

absent in normal tissues [2]. In this study, we used realtime RT-PCR to detect PRAME gene expression, and relative gene expression data were analysed with the $2^{-\Delta \Delta \mathrm{Ct}}$ method. Only one of fifteen normal bone marrow samples from individuals with non-malignant haematological diseases showed weak PRAME gene expression. In contrast, 30 of 61 patients (48.39\%) with AML and 7 of 19 patients (36.84\%) with ALL showed PRAME expression, and the difference in PRAME expression between AML and ALL cases was not statistically significant, which was in agreement with previous reports [7]. The highest prev- 
Fig. 5. Relative TRAIL levels in control and patient groups (expressed in $\Delta \mathrm{Ct}$ ). Horizontal lines represent the mean relative TRAIL expression of each study group. A high $\Delta \mathrm{Ct}$ value indicates a low TRAIL expression level.

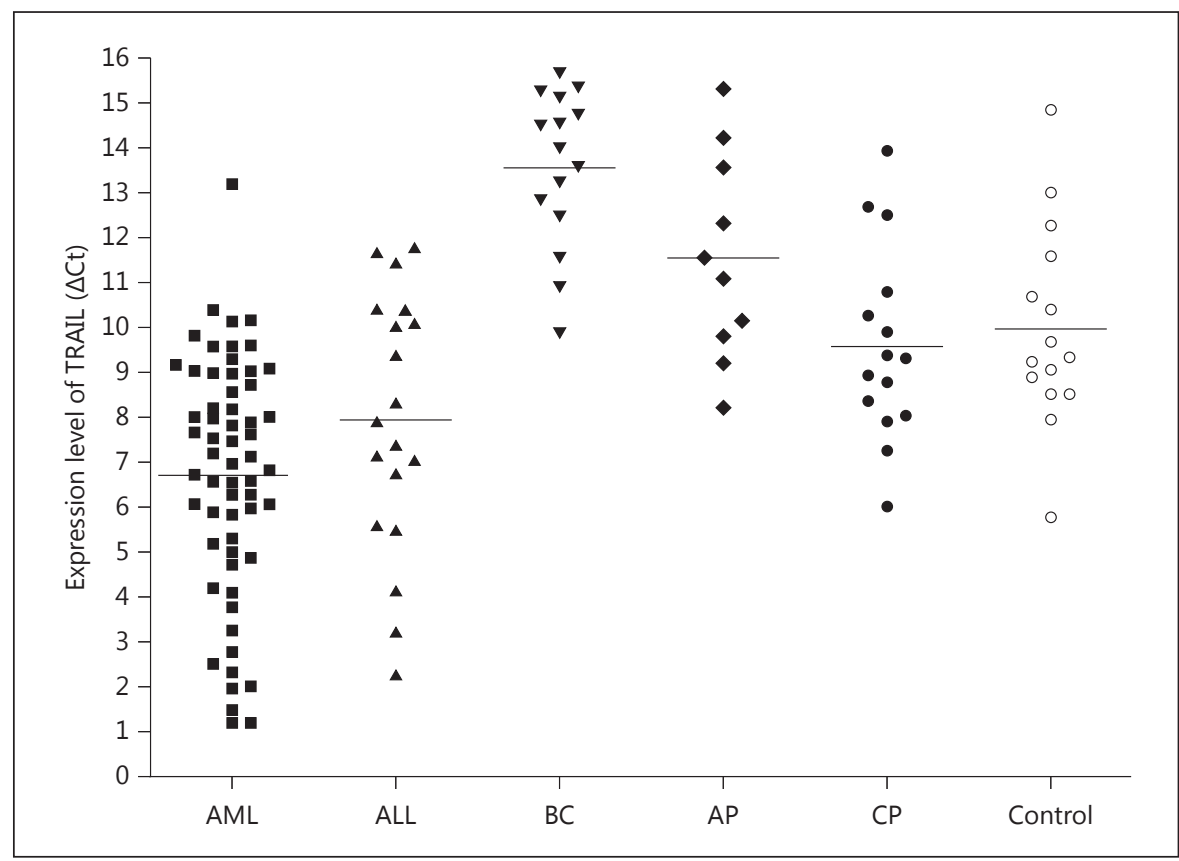

alence has been found in M2 and M3 phenotypic subgroups and in cases with $t(8 ; 21)$ [8]. Tajeddine et al. [5] demonstrated that the expression of PRAME and AML1/ ETO transcripts was highly correlated. In our study, PRAME was found in $100 \%$ of patients with the $t(8 ; 21)$ translocation in $\mathrm{M} 2$ and $60 \%$ of patients with the $\mathrm{t}(15 ; 17)$ translocation in M3. We monitored PRAME expression in 4 PRAME-positive patients with the AML1/ETO fusion gene, and PRAME expression decreased significantly after induction therapy in all 4 . This finding indicates that PRAME could serve as a marker for monitoring minimal residual disease (MRD) in AL. We also found an inverse correlation between PRAME expression and blast cells in the marrow of AML patients, which was in line with the findings of Steinbach et al. [9]. PRAME expression has been studied in a relatively limited number of cases with CML, and the data on PRAME expression are highly variable. PRAME expression was not detected in a study of 13 cases [8]. In another study by Matsushita et al. [7], 32 CML cases were evaluated, and PRAME expression was identified in $31 \%$; there was a trend towards increased PRAME expression in advanced-stage disease. Watari et al. [10] proposed that PRAME was a BCR-ABL inducible gene, and this hypothesis was proven by De Carvalho et al. [4]. In our study, 15 cases had CP disease and 2 of these had PRAME expression (13.33\%), 10 cases had AP disease and 4 of these had PRAME expression (40\%) and 12 of the 15 cases with BC had PRAME expres- sion (80\%). We found an obvious trend towards increased PRAME expression in CML patients with advanced-stage disease, which was in line with previous research $[4,6,7]$. Van 't Veer et al. [11] suggested PRAME as an independent prognostic marker of poor clinical outcome in different solid tumours, while another group viewed PRAME as a marker of favourable prognosis in childhood AML patients [12].

TRAIL can only induce apoptosis in cancer cells, and increasing evidence has shown that TRAIL is capable of acting as a tumour suppressor. On the one hand, experiments using neutralising antibodies against TRAIL proved that it could significantly increase liver metastases in mice [13]. On the other hand, TRAIL-knockout mice were more susceptible to tumourigenesis induced by metastasis and chemical carcinogens [13]. In fact, according to some expression-profiling surveys in cancer, upon cancer progression, TRAIL expression is lost [14]. These data indicate that TRAIL down-regulation plays an important role in tumour initiation and progression. TRAIL expression has been studied in a relatively limited number of leukaemia cases. In our study, TRAIL expression in the CML group was significantly lower than in normal controls. Patients with lower TRAIL expression were in the advanced phases of the disease, while patients with higher expression were in the $\mathrm{CP}$, which indicates that decreased TRAIL expression may play an important role in the pathogenesis of CML. In contrast to CML, TRAIL 
expression in the AML and ALL groups was significantly higher than in controls. A previous study used RT-PCR to detect the TRAIL gene in leukaemia cells, and the results showed that malignant cells from most cases of primary AML and ALL had positive TRAIL expression [15], which is in line with our results. TRAIL is involved in the tumour cell evasion of immunosurveillance through killing activated human T cells, and TRAIL could be related to spontaneous tumour cell death and necrosis [16]. Therefore, we hypothesise that TRAIL up-regulation in AL might play a role in tumour initiation. In our study, TRAIL expression at CR showed high variability compared with its expression at presentation. This finding may indicate that TRAIL itself is not a candidate for monitoring MRD, and the simultaneous detection of TRAIL and PRAME is necessary to monitor MRD.

De Carvalho et al. [4] detected PRAME and TRAIL gene levels in peripheral blood mononuclear cells from CML patients using RQ-PCR. He found a significant inverse correlation between the expression of these two genes, and knocking down the PRAME gene with RNA interference restored TRAIL gene expression in a BCRABL-positive cell line. The BCR-ABL-mediated up-regulation of PRAME directly resulted in TRAIL down-regulation in BCR-ABL-positive cells [4]. TRAIL down-regulation by PRAME may be a more general phenomenon in a variety of tumours, as indicated by in silico analyses in gene-expression-profiling studies. De Carvalho et al. [4] hypothesised that TRAIL expression may be regulated by PRAME because PRAME is a dominant repressor of RA receptor signalling [17] and TRAIL is inducible by RA treatment. However, the mechanism via which PRAME suppresses the RA signalling pathway has only been well established in melanoma, and whether PRAME inhibits RA signalling in other tumours is not clear. In fact, in AL,
PRAME expression was not associated with down-regulation of RA signalling [18]. We detected PRAME and TRAIL gene expression in bone marrow mononuclear cells from leukaemia patients with RQ-PCR, and our result was in line with the conclusion of De Carvalho et al. [4] that there was a significant inverse correlation between the expression of these two genes in CML cases. More importantly, we found a more significant correlation between this expression in an advanced phase, but there was no correlation in CML-CP cases. In addition, no correlation was observed between the levels of these two genes in AL patients. To date, these observations have not been presented in the literature. The combined treatment of TRAIL production with imatinib enhances the TRAIL-induced apoptosis of BCR-ABL-positive cell lines, even K562, a TRAIL-resistant cell line [19], and it has been proven that K562 cells with an artificial reduction in PRAME expression are more sensitive to imatinib because of increased TRAIL expression [4]. Therefore, we hypothesise that interfering with PRAME expression combined with methods that stimulate TRAIL up-regulation may be a good alternative or co-adjuvant strategy for CML patients. In contrast, there was no inverse correlation between the levels of these two genes in AL cases, which may be because PRAME is not associated with down-regulation of RA signalling in AL cases; therefore, PRAME could not down-regulate TRAIL by suppressing the RA signalling pathway.

\section{Acknowledgements}

This work was supported by the Institute of Hematology, Henan Provincial People's Hospital.

\section{References}

$>1$ Ikeda H, Lethe B, Lehmann F, van Baren N, Baurain JF, de Smet C, Chambost H, Vitale M, Moretta A, Boon T, Coulie PG: Characterization of an antigen that is recognized on a melanoma showing partial HLA loss by CTL expressing an NK inhibitory receptor. Immunity 1997;6:199-208.

-2 van Baren N, Brasseur F, Godelaine D, Hames G, Ferrant A, Lehmann F, André M, Ravoet C, Doyen C, Spagnoli GC, Bakkus M, Thielemans K, Boon T: Genes encoding tumor-specific antigens are expressed in human myeloma cells. Blood 1999;94:1156-1164.

Correlation between PRAME and TRAIL

Gene Expression in Leukaemia
3 Wiley SR, Schooley K, Smolak PJ, Din WS, Huang CP, Nicholl JK, Sutherland GR, Smith TD, Rauch C, Smith CA: Identification and characterization of a new member of the TNF family that induces apoptosis. Immunity 1995;3:673-682.

4 De Carvalho DD, Binato R, Pereira WO, Leroy JM, Colassanti MD, Proto-Siqueira R, Bueno-Da-Silva AE, Zago MA, Zanichelli MA, Abdelhay E, Castro FA, Jacysyn JF, Amarante-Mendes GP: BCR-ABL-mediated upregulation of PRAME is responsible for knocking down TRAIL in CML patients. Oncogene 2011;30:223-233.

\footnotetext{
5 Tajeddine N, Millard I, Gailly P, Gala JL: Realtime RT-PCR quantification of PRAME gene expression for monitoring minimal residual disease in acute myeloblastic leukaemia. Clin Chem Lab Med 2006;44:548-555.

-6 Radich JP, Dai H, Mao M, Oehler V, Schelter J, Druker B, Sawyers C, Shah N, Stock W, Willman CL, Friend S, Linsley PS: Gene expression changes associated with progression and response in chronic myeloid leukaemia. PNAS 2006;103:2794-2799.
} 
7 Matsushita M, Ikeda H, Kizaki M, Okamoto S, Ogasawara M, Ikeda Y, Kawakami Y: Quantitative monitoring of the PRAME gene for the detection of minimal residual disease in leukaemia. Br J Haematol 2001;112:916926.

8 van Baren N, Chambost H, Ferrant A, Michaux L, Ikeda H, Millard I, Olive D, Boon T, Coulie PG: PRAME, a gene encoding an antigen recognized on a human melanoma by cytolytic T cells, is expressed in acute leukaemia cells. Br J Haematol 1998;102:1376-1379.

-9 Steinbach D, Henmann J, Viehmann S, Zintl F, Gruhn B: Clinical implication of PRAME gene expression in childhood acute myeloid leukaemia. Cancer Genet Cytogenet 2002; 133:118-123.

10 Watari K, Tojo A, Nagamura-Inoue T, Nagamura F, Takeshita A, Fukushima T, Motoji T, Tani K, Asano S: Identification of a melanoma antigen, PRAME, as a BCR/ABL inducible gene. FEBS Lett 2000;466:367-371.
11 van 't Veer LJ, Dai H, van de Vijver MJ, He YD, Hart AA, Mao M, Peterse HL, vander Kooy K, Marton MJ, Witteveen AT, Schreiber GJ, Kerkhoven RM, Roberts C, Linsley PS, Bernards R, Friend SH: Gene expression profiling predicts clinical outcome of breast cancer. Nature 2002;415:530-536.

12 Tajeddine N, Louis M, Vermylen C, Gala JL, Tombal B, Gailly P: Tumor-associated antigen PRAME is a marker of favorable prognosis in childhood acute myeloid leukaemia patients and modifies the expression of S100A4, Hsp27, p21, IL-8 and IGFBC-2 in vitro and in vivo. Leuk Lymphoma 2008;49:1123-1131.

13 Cretney E, Takeda K, Yagita H, Glaccum M, Peschon JJ, Smyth MJ: Increased susceptibility to tumor initiation and metastasis in TNFrelated apoptosis-inducing ligand-deficient mice. J Immunol 2002;168:1356-1361.

14 Daniels RA, Turley H, Kimberley FC, Liu XS, Mongkolsapaya J, Ch'En P, Xu XN, Jin BQ, Pezzella F, Screaton GR: Expression of TRAIL and TRAIL receptors in normal and malignant tissues. Cell Res 2005; 15:430-438.

15 Zhao S, Asgary Z, Wang Y, Goodwin R, Andreeff $M$, Younes A: Functional expression of TRAIL by lymphoid and myeloid tumor cells. Br J Haematol 1999;106:827-832.
6 Jeremias I, Herr I, Boehler T, Debatin KM: TRAIL/Apo-2-ligand-induced apoptosis in human T cells. Eur J Immunol 1998;28:143152.

17 Epping MT, Wang L, Edel MJ, Carlee L, Hernandez M, Bernards R: The human tumor antigen PRAME is a dominant repressor of retinoic acid receptor signaling. Cell 2005;122: 835-847.

18 Steinbach D, Pfaffendorf N, Wittig S, Gruhn B: PRAME expression is not associated with down-regulation of retinoic acid signaling in primary acute myeloid leukaemia. Cancer Genet Cytogenet 2007;177:51-54.

19 Nimmanapalli R, Porosnicu M, Nguyen D, Worthington E, O’Bryan E, Perkins C, Bhalla $\mathrm{K}$ : Cotreatment with STI-571 enhances tumor necrosis factor alpha-related apoptosis-inducing ligand (TRAIL or apo-2L)-induced apoptosis of Bcr-Abl-positive human acute leukaemia cells. Clin Cancer Res 2001;7:350357. 